\title{
School truancy among Turkish high school students: A test of General Strain Theory
}

\author{
Ozgur Solakoglu, \\ Ugur Orak ${ }^{2}$
}

\begin{abstract}
School absenteeism is a complicated problem with a variety of causes. It has been shown to be one of the main predictors of school drop-outs as well as leading to delinquency and criminal behavior in adulthood. This study examines the applicability of General Strain Theory on educational factors by considering truancy as a risk behavior. In this empirical study, we test the explanatory powers of certain kinds of strain, including school strain, economic deprivation, negative life events, anger, college plans, past victimization, and depression on students' truancy. Data were drawn from the part of 2008 Youth in Europe Survey conducted in Istanbul in 2008. The sample consists of 2445 high school students. Results indicate that school strain, anger, and negative life events are significantly associated with likelihood of truancy while past victimization and economic strain have no effect. College goal and depression, on the other hand, have relatively weaker effects on students' school absenteeism. Findings revealed that there is a relationship between cutting classes and certain kinds of strain among Turkish adolescents. The study also demonstrates that General Strain Theory is applicable for problematic behaviors in an educational context and generalizable to countries other than the U.S.
\end{abstract}

Keywords: School Absenteeism; Truancy; Risk Behaviors; General Strain Theory; Strain

\section{INTRODUCTION}

School absenteeism is a very complex concept with a variety of causes and destructive consequences. Authors describe school absenteeism using many definitions. According to Ingul, Klockner, Silverman, and Nordahl (2012, p.93), every student is absent from school on occasion, and therefore, we should examine absences using two different categories: (1) excusable absenteeism, which is unproblematic and caused by issues such as illness, and (2) inexcusable absenteeism, which is absence without reason, also called truancy or "cutting class". Most studies distinguish between students who report excuses for their absences from those who do not (Ingul et al., 2012; Ingul \& Nordahl, 2013; Gage, Sugai, Lunde \& DeLoreto, 2013). In the current study, we draw from Kearney's (2008, p.452) definition of school absenteeism, in other words: truancy, that it is defined as inexcusable absences of students in primary and high schools in Istanbul, Turkey.

According to Steinhart (1996, p.86), truancy, or unexcused school absenteeism is considered a status offence, similar to underage drinking, by most of the states in the U.S. However, legal

\footnotetext{
${ }^{1}$ Corresponding Author: Ph.D., Turkish Military Academy, Defense Science Institution, ozgursolakoglu@gmail.com
}

2 M.A., Louisiana State University, Department of Sociology, ugurorak06@gmail.com 
sanctioning of unexcused school absenteeism can vary depending on the country. In Turkey, for example, per school years, students have a right to be absent from school for 45 days in total. Students with more than 20 excused absences or more than 45 unexcused absences, will fail their grades and must retake classes again. Along with its penal sanctioning, unexcused school absenteeism can result in several destructive outcomes. According to Kearney (2008, p.459), for instance, unexcused school absenteeism is one of the main predictors of school drop-outs. Ingul et al. (2013) state that unexcused school absenteeism can also cause major behavioral disorders which lead adolescents to anxiety, binge drinking, drug use, and even suicide attempts while enhancing the probability of unemployment and general economic deprivation in adulthood.

In order to deter these destructive outcomes of school absenteeism, researchers have recently focused on determining its causes. In this vein, various factors, such as boredom in the classroom, insufficient interest in classes, unnecessary classes, punishments, and bad relations with teachers have been found to be primary indicators of school absenteeism rates (DeKalb, 1999, p.3). In addition, Ingul et al. (2012) found that anxiety, depression, safety at school, and parental unemployment works as risk factors for school absenteeism.

Though unexcused school absenteeism is a growing problem in developing and undeveloped countries, it is a relatively understudied topic. Turkey, for example, as a developing Muslim country, in which the cultural values, educational system, and social structure are different from those in the U.S., is an exceptional research setting for scholars interested in risk behaviors in the educational context of different countries (Yilmaz, Lo \& Solakoglu, 2015). Using a Turkish dataset, this study aims to expand the exploration of school absenteeism in these countries.

On the other hand, since its introduction in 1992, General Strain Theory, which suggests that certain kinds of strain increase the likelihood of crime, delinquency, and risky behaviors, has been supported by numerous studies. With a few exceptions, however, most of these studies have been conducted in the United States. This has created an issue for the generalizability of general strain theory, especially to countries influenced by Eastern culture and Islamic beliefs. Another goal of this study is therefore, to test the generalizability of the General Strain Theory to Eastern and Muslim countries.

Although there are many studies indicating the causes for school absenteeism, especially in the American literature, none of them evaluate the influence of various types of strain. Hence, the final goal of this study is to apply a criminological perspective to the explanations for school absenteeism. Thus, we also aim at demonstrating the applicability of General Strain Theory on educational issues by analyzing unexcused school absenteeism as a risk behavior.

\section{BACKGROUND}

\subsection{General Strain Theory}

General Strain Theory is a criminological theory developed by Robert Agnew (1992) in response to the theoretical and empirical criticisms of classical strain theories. He hoped it would to serve as a complement to the criminological theories dominating the field at that time. Prior to 1992, classical strain theories focused mainly on two factors. First, these theories focused on the effect of negative relationships with others. This refers to "the relationship in which the individual is not treated as he or she wants to be treated" (Agnew, 1992, p.48). Second, the theories focused on the relationship in which individuals' positively valued goals are failed to be achieved (Agnew, 1992). These early strain theories were criticized due to their limited scope. They mainly focused on delinquency among lower class individuals in urban environments (Cloward \& Ohlin, 1959; Cohen, 1955; Merton, 1938). They also assumed that there is an inverse relationship between crime and class, an assumption that has been controversial for decades (Braithwaite 1981; Kleck, 1982; Tittle \& Meier, 1990). These theories also suggested that strain is a direct cause of crime and delinquency. 
However, not all individuals who experience strain commit crimes or engage in delinquent activity (Smith, 1979). Given these limitations and controversies, classical strain theories have always been problematic for researchers. Thus, Agnew (1992) developed General Strain Theory in order to complement classical theories and respond to their controversies. The best way to understand General Strain Theory is to consider its differences from classical strain theories.

Classical theories focus explicitly on strain as a consequence of loss of positive stimuli. General strain theory, however, broadens the focus by including the presence of negative stimuli in addition to the loss of positive stimuli as a strain source (Agnew, 1992). While the preservation of negative stimuli may occur in some different conditions, such as homelessness, adverse relations with parents, and negative school experiences; broken relationships with a loved one's or the death of a parent may be good examples of loss of positive stimuli. Both causes lead people to be involved in criminal action in order to remove negative stimulus or to prevent loss of positive stimulus. According to classical theories, however, economic failure, meaning the loss of positive stimuli, is the most important factor increasing people's strain level and stimulating them to achieve their economic goals by participating in crime. Contrary to the economic assumptions of classical theories, General Strain Theory states that strain may result not only from the loss of positive stimuli, but also from the inability to escape negative stimuli, which may also lead one into criminal behavior (Agnew, 2006; Kubrin, Stucky \& Krohn, 2009). In the light of this new insight, many previous studies supported the link between different kinds of strain and criminal/risk behavior by utilizing General Strain Theory though most of them were produced by scholar from Western countries (Aseltine, Gore \& Gordon, 2000; Broidy, 2001; Piquero \& Sealock, 2004; Patchin \& Hinduja, 2010; Sigfusdottir, Kristjansson \& Agnew 2012; Reid \& Piquero, 2013; ).

\subsection{School Absenteeism}

Although there are a variety of definitions of school absenteeism formulated by different social scientists, it can be basically defined as excused or unexcused absences of students in primary and high schools (Kearney, 2008, p.452). Recently, school absenteeism has attracted researchers' and policy makers' interest as a serious public problem. However, it is a very complex issue associated with many social, psychological, and environmental factors. In educational literature, school absenteeism has been generally examined in two different categories; (1) excusable school absenteeism and (2) inexcusable school absenteeism (Ingul, Klockner, Silverman \& Nordahl, 2012; Ingul \& Nordahl, 2013; Gage, Sugai, Lunde, \& DeLoreto , 2013). School absenteeism is excusable if it is caused by illness, medical appointments, or other unavoidable reasons. Excusable absenteeism is generally seen as not problematic. Unexcusable school absenteeism, on the other hand, also known as truancy or school refusal (Ingul et al., 2012), is very problematic. In most of the countries and some states in the US, truancy is considered an offence by juvenile justice system and truants are subject to punishment (Fantuzzo, Grim \& Hazan, 2005). Along with its penal sanctioning, it can also result in perilous social, psychological, and economic problems for adolescents. According to Kearney (2008), for instance, unexcused school absenteeism is one the main predictors of school drop-outs. Besides, Ingul et al. (2013, p.94) state that unexcused school absenteeism can also cause major behavioral disorders which lead adolescents to anxiety, binge drinking, drug use, and even suicide attempts while enhancing the probability of unemployment and economic deprivation in adulthood period. In a similar vein, Eaton, Brener and Kann (2008) found that students who are absent without permission are more likely to exhibit some psychiatric disorders or risk behaviors such as violence, tobacco use, binge drinking, drug use, and risky sexual behaviors. In addition, Egger, Costello and Angold (2003) assert that along with its dangerous psychiatric results, unexcused school absenteeism gives rise to sleep difficulties, higher rates of worries, headaches, stomachaches, poorer peer relations, and lower socioeconomic status. Since unexcused school absenteeism can cause such devastating social, psychological, and economic problems in an adolescents' life, it is generally considered a risk behavior or a problematic behavior 
Solakoglu O.,\& Orak, U. (2016). School truancy among Turkish high school students: A test of General Strain Theory. International Journal of Human Sciences, 13(1), 1460-1472. doi:10.14687/ijhs.v13i1.3670

in educational literature (Beyth-Marom, Austin, Fischhoff, Palmgren \& Jacobs-Quadrel 1993; Eaton et al., 2008; Ingul et al., 2013).

\subsection{Causes of School Absenteeism}

Due to growing concerns about the destructive outcomes of school absenteeism, researchers have aimed to determine the causes leading students to school absenteeism. In educational literature, some factors such as boredom in the classroom, insufficient interest in classes, unnecessary classes, punishments, and bad relations with teachers are highlighted as prominent indicators of school absenteeism rates (DeKalb, 1999, p.3). In addition, having difficulties making friends, having no reason to continue school, and social loneliness at school appear as other factors. Furthermore, Ingul et al. (2012) find that anxiety, depression, safety at school, and parental unemployment function as risk factors for school absenteeism. They also state that major risk factors for school absenteeism are family, work, health, and school environment (Ingul et al. 2012). Their results show that some strain variables such as depression, anxiety, and school strain play an important role on students' school absenteeism. In parallel, Ingul et al. (2013) assert that anxiety disorders and economic deprivation are strongly associated with school absenteeism. Interestingly, they also imply that anxious students who attend school regularly report that they experience more bullying and develop distrust for the school environment.

\subsection{School Absenteeism in Turkey}

As is the case with many countries worldwide, school absenteeism is also an important problem in Turkey, which is a developing country under the effect of Eastern culture that is very different from the U.S. According to Turkish laws, high school students have a right of being absent for 45 days per a school year. Students with more than 20 excused absences, or more than 45 unexcused absences, fail the current grade. Because of these penal sanctions, absenteeism causes school dropouts for many students and in turn reduces their job opportunities in adulthood. According to an investigative report published by Turkish Ministry of National Education in 2013, school absenteeism rates for high school students, both excused and unexcused, is 32.7 percent in Turkey (Polat, 2013). Moreover, as we can see in Table 1, 10.8 percent of these students skip school for 20 days or more, putting them at risk for failure. The report also shows that unexcused school absenteeism rates are around 6 percent among high school students and rates have continued to increased annually since 2003 (Polat, 2013).

Table 1: Proportions of Absent Students by Amount of Days in 2013

\begin{tabular}{llllllll}
\hline 3 days & 5 days & 7 days & 10 days & 14 days & 20 days & 22 days & $23+$ days \\
& & & & & & & \\
\hline $52 \%$ & $14.4 \%$ & $9.7 \%$ & $7.8 \%$ & $5.3 \%$ & $4.8 \%$ & $1.2 \%$ & $4.8 \%$
\end{tabular}

Source: Turkish Ministry of National Education Investigation Report (2013)

Since school absenteeism has emerged as an important social problem in Turkey, this has attracted researchers' interest, and thus, many studies have been conducted recently. These studies have presented both causes and results of the unexcused school absenteeism in the Turkish context. In general, causes of school absenteeism found in the Turkish context have included students' lack of interest in schooling, cultural beliefs alleging that schooling is unnecessary for girls, economic factors encouraging students to work in a job for their families, students' family structure, adverse 
situations resulting from administrators' and teachers' behaviors, and bullying in school (Baker, Sigmon \& Nugent 2001; Pehlivan, 2006).

Pehlivan (2006) divides reasons of school absenteeism into three categories from teachers' perspectives. The first is parental reasons, including domestic violence, cruel treatment, marital discord, and lower parental educational levels. Pehlivan (2006) specifies the second category as educational reasons, including lack of opportunities for students to study their special interests, deficiencies of teachers in terms of using the best teaching method, and insufficient communication between school personnel and parents. The last category includes student-based reasons, including peer groups and problems related to adolescence (Pehlivan, 2006). In the same study, Pehlivan (2006) also examines reasons for school absenteeism from students' perspectives. Students state that they cut classes because they are bored in classes, dislike their classes, are negatively influenced by peer groups, and have low educational expectations. This demonstrates that there is a difference between students' and teachers' perceptions of reasons for school absenteeism.

In another study related to school absenteeism in Turkey, Altınkurt (2008, p.130) addresses six dimensions of causes of school absenteeism: (1) Problems caused by school administrators, such as specifying class hours, break times, and passing over students' views on school-related problems; (2) Problems caused by teachers, such as authoritarian manners in the class, insufficient communication with students, having unattainably high expectations from students, and bad behaviors in the class; (3) Problems caused by family, such as educational levels of parents, divorce, and excessive parental control of parents over their kids; (4) Environmental reasons, such as peer groups, distance of students' houses to the school, and other physical factors; (5) Academic anxieties, such as bad grades on exams and poor study habits; and (6) Individual reasons, such as psychological disorders, unhealthiness, necessity of working outside the school (Altunkurt, 2008, p.131).

In addition to the reasons mentioned above, there are other reasons for school absenteeism unique to Turkey. Although Turkey is a developing country which is affected by both Eastern and Western cultural beliefs, dogmatic cultural beliefs still occur among some people, especially those living in rural areas of the country. In these conditions, gender appears as an important factor for school absenteeism. According to Adigüzel (2013, p.333), girls face many difficulties in attending school in Turkey. The cultural belief asserting that education is unnecessary for girls and women, who are expected to be housewives and to raise children, is an especially important factor for girls' unexcused school absenteeism. Along with this belief, the lack of successful female role-models in rural areas is another factor reducing girls' expectations from life and their educational success (Adigüzel, 2013, p.342). In addition, another important issue related of school absenteeism in Turkey is the country's geographical position. The high mountains covering the eastern part of the country can constitute a difficulty for students to go to school (Kiran, 1999).

As a result, for Turkish researchers and policy makers, school absenteeism is a growing concern in Turkey, a developing country aimed at improving its educational system. Reasons for school absenteeism change depending on geographical areas, cultural systems, religious beliefs and other factors. This demonstrates the complexity of the problem along with its growing rates in the country.

\section{RESEARCH QUESTIONS AND HYPOTHESES}

Unexcused school absenteeism is generally seen as a risk behavior in educational literature. General Strain Theory suggests that crime, delinquency and risk behaviors are actions that are committed under the condition of strain and pressure. Considering the main assumptions of General Strain Theory, we asked three research questions:

Is there any relationship between cutting classes and stressful conditions among Turkish high school students? What kinds of strain are directly and significantly related to unexcused school 
absenteeism? Can General Strain Theory be applied to the area of education and is it generalizable to Eastern countries? Is there any gender differences, considering the link between truancy and different kinds of strains?

Based on our theoretical approach and findings of studies in the related literature mentioned above, the hypothesis below were tested to understand the relationship between strain and school absenteeism, focusing mainly on the following seven strain variables: (1) School strain; (2) Economic deprivation; (3) Negative life events; (4) Anger; (5) College Plans; (6) Past Victimization; and (7) Depression. Based on the theory and a review of the literature, the following hypothesis guided the analysis: each of the strain variables would be significantly associated with likelihood of chronic truancy.

\section{METHODOLOGY}

\subsection{Data}

Data was drawn from the "2008 Youth in Europe Survey", a set of cross sectional surveys conducted on 15 to 16-year-old adolescents in 11 cities across Europe. Istanbul, which is one of these 11 participant cities, with a sample of 2445 students was selected for the analysis. Surveys was administered and coordinated by Reykjavik University and University of Iceland in close cooperation with the participant cities in the program. For this study, Istanbul, which is the biggest city of Turkey with 15 million inhabitants, was selected as a participant city for three reasons: (1) Sufficiency of data; (2) High response rate; and (3) its cultural and religious values which may affect the relationship between strain and school absenteeism differently from those in the US. All classes from all schools within the city were randomly sampled for participation, and teachers in the classes guided data collection.

The sample was selected from the high school students in Bagcilar, a district of Istanbul/Turkey. Istanbul is one of the most prominent cities in Europe with its rich cultural and historical background, and it is also the most crowded city in Turkey. While Bagcilar is a district, it has a population of 720,000 people that is more crowded than 52 out of 81 cities of Turkey. The youth population in this district is 22,075 , and a simple random sample of 2445 students was selected.

\subsection{Measurements}

\subsubsection{Dependent Variable}

The dependent variable of this study is truancy which is unexcused school absenteeism. Unexcused school absenteeism was measured by students' responses to the following question: "How many whole days have you been absent from school during the last 30 days without any excuses?" Many "zero" responses given for the question of school absenteeism created a distribution that was positively skewed, thus violating the normal distribution of the dependent variable. In addition, after examining the distribution of the dependent variable, it appears that there are three different group of students: those who do not engage in truancy, students who were involve in infrequent truancy, such as 1 or 2 days, and those who are absent several times without any excuse. Similar subgroups were observed in the study of Gage, Kuo, Coller, Guerrero, \& Wong (2014), examining the truancy among American students. With this respect, students were classified as $0=$ "Never Truant", $1=$ "Infrequent truancy" ( 1 and 2 days) and 2= "Chronic Truancy" (3-4 days, 5-6 days, 7 days and more") 


\subsubsection{Independent Variables}

School strain was measured with an index consisting of the following nine items: (1) I find the studies pointless; (2) I am bored with the studies; (3) I am poorly prepared for classes; (4) I feel I do not put enough effort into the studies; (5) I find the studies too difficult; (6) I feel bad at school; (7) I want to quit school; (8) I want to change schools; and (9) I get on badly with the teachers. Possible respond categories were: 1="Applies almost never to me", 2="Applies seldom to me", $3=$ "Applies sometimes to me", 4="Applies often to me", and 5="Applies almost always to me". The scores of respondents were summed and divided by the number of questions to keep the original scale ranging from 1 to $5(\alpha=.96)$ Final scores were reverse coded. Thus, a higher score indicates higher school strain.

The following four items were used to create an index measuring economic deprivation (1) Parents are poorly-off financially; (2) Parents can't afford to have a car; (3) Parents hardly have enough money to pay for necessities; and (4) parents do not have enough money to pay for extracurricular activities. The response choices consist of 5 categories ranging from $1=$ "Almost Never" to $5=$ Almost always". Similar to school strain, responses were summed and divided by the number of questions with an adequate alpha score $(\alpha=.92)$. A higher score refers to higher economic deprivation.

The negative life events is a count variable measuring the number of negative life events that respondents experienced in last 12 months. Response categories are $0=$ "No" and $1=$ "Yes" for each of the following negative life events: (1) Serious accident; (2) severe illness; (3) separation or divorce of your parents; (4) break up with a girl/boyfriend; (5) serious argument with your parents; (6) witnessed a serious argument by your parents; (7) witnessed physical violence in your home where an adult was involved; (8) been involved in physical violence in your home where an adult was involved; (9) death of a parent or sibling; (10) death of a friend; and (11) been rejected by your friends.

Anger as an index measured by the following moods of respondents during the last week: (1) I was easily annoyed or irritated; (2) I experienced outbursts of anger that I could not control; (3) I wanted to break or damage things; (4) I had a row with someone; and (5) I yelled at somebody or threw things. The response categories range from 1="Almost Never" to $4=$ "Often". Responses were summed and divided by the number of questions $(\alpha=.98)$.

Depression was measured by responses given for the following situations: (1) I was sad or had little interest in doing things; (2) I had little appetite; (3) I felt lonely; (4) I cried or wanted to cry; (5) I had sleeping problems; (6) I felt sad or blue; (7) I was not excited in doing things; (8) I was slow or had little energy; (9) The future seemed hopeless; and (10) I thought of committing suicide. The response categories range from $1=$ Almost Never to $4=$ Often. An index was created by summing responses and dividing by the number of questions with an adequate alpha score $(\alpha=.98)$.

College plan was measured by responses given for the question: "What do you think you will do after graduating from this school?" It has six categories depending on the following responses; (1) go to college or upper high school, (2) go to trade school or similar, (3) start working or looking for a job, (4) study abroad, (5) work abroad, and (6) nothing. It was treated as a dichotomous variable with $0=$ no college plans and $1=$ having college plans.

Past victimization was treated as a dichotomous variable. The respondents were asked whether they have been a victim of physical violence in the last 12 months. The variable was coded as $1=$ ="Never", $2=$ "Once", 3="2-5 times", 4= "6-9 times", $5=$ "10-13 times", $6=$ " $14-17$ times', $7=$ "18 times or more". 
Solakoglu O.,\& Orak, U. (2016). School truancy among Turkish high school students: A test of General Strain Theory. International Journal of Human Sciences, 13(1), 1460-1472. doi:10.14687/ijhs.v13i1.3670

\subsubsection{Control Variables}

Age is a demographic factor, which may affect dependent variables significantly. In this study, age, as an interval variable, ranged from 12 to 17 because the survey was conducted on students who were in 8th, 9th, and 10th grades in their schools. The variable was centered to improve the ease of interpretation. Gender is another demographic factor affecting both students' and parents' attitudes on school absenteeism. In this study, gender of respondents was treated as a dichotomous variable, coded as 1 for male and 0 for female. Respondents' family structure was measured by dividing respondents into two groups with $0=$ lives with both parents and $1=$ other arrangements.

\subsection{Analytic Strategy}

Since the dependent variable is not normally distributed, ordinal logistic regression was used to assess the likelihood of truancy. We presented six different models of ordinal logistic regression analyses. First, two models were run using the total sample, while other models were conducted with gender subsamples. In the first model, third model and fifth model, only the key independent variables (school strain, economic deprivation, negative life events, anger, and depression) were included to understand the relationship between school absenteeism and certain kinds of strain. In other models, control variables were added to the analysis to observe differences in this relationship when students' age, gender, and family structures were held constant. The model with a higher explanatory power was selected and interpreted.

\section{RESULTS}

\subsection{Descriptive Results}

Table 2: Descriptive Statistic of Variables Used in the Study $(\mathrm{N}=1902)$

\begin{tabular}{|c|c|c|c|c|c|}
\hline Variables & Mean & SD & Min & Max & Correlation \\
\hline Truancy & 0.28 & 0.59 & 0 & 2 & 1 \\
\hline No Truancy (0) & $77.46 \%$ & & & & \\
\hline Infrequent Truancy (1) & $15.30 \%$ & & & & \\
\hline Chronic Truancy (2) & $7.41 \%$ & & & & \\
\hline School Strain & 2.40 & 0.77 & 1 & 5 & $.22 * * *$ \\
\hline Negative Life Events & 0.56 & 1.15 & 0 & 11 & $.10^{* * *}$ \\
\hline Economic Deprivation & 2.17 & 0.97 & 1 & 5 & .03 \\
\hline Anger & 2.05 & 0.79 & 1 & 4 & $.17 * * *$ \\
\hline Depression & 2.02 & 0.81 & 1 & 4 & $.08^{* * *}$ \\
\hline Having College Goal & 0.90 & & 0 & 1 & $-.12 * * *$ \\
\hline Victimization & 0.20 & 0.76 & 0 & 6 & $.08^{* * *}$ \\
\hline Male & 0.51 & & 0 & 1 & $.15^{* * *}$ \\
\hline Living With Both Parents & 0.92 & & 0 & 1 & $-.07 * * *$ \\
\hline Age & 2.65 & 0.68 & 0 & 4 & $-.16^{* * *}$ \\
\hline
\end{tabular}


Table 2 presents descriptive statistics for dependent, independent, and control variables analyzed in the study. Starting with our dependent variable, the majority of students $(77.46 \%)$ reported that they did not skip school in the last 30 days. On the other hand, 15.30 percent of the students were involved in infrequent truancy ( 1 or 2 days). Finally, a small number $(7.41 \%)$ of respondents engaged in chronic truancy.

An examination of the students' demographic structure revealed there were an almost equal number of boys (51\%) and girls (49\%) with just a few more boys. Most of students (92\%) lived with both of their parents and the average age was 16.5 with a standard deviation of .68. As stated earlier, students' school strain was analyzed using an index ranging from 1 ("Applies always to me") to 5 ("Applies almost never to me"). The average score on the index was 2.40 with a standard deviation of .77, meaning that students, on average, feel school strain sometimes. Just as we did for school strain, we measured economic deprivation of students with the Likert Scale ranging from 1 to 5. Descriptive analysis revealed that students generally chose first (almost never), second (seldom), and third choices (sometimes), showing that most of students do not have large economic strain.

Students' negative life events were treated as a summative score consisting of 13 different events, all of which were dichotomous variables. As seen in Table 1, the average mean score was .56 with a standard deviation of 1.15 on the summative index of negative life events ranging from 1 event to 11 events, meaning the majority of respondents did not experienced negative life events. On average, respondents are seldom angry, based on the scale measuring anger of students consisting of 4 items ranging from almost never (1) to often (4). A similar scale ranging from 1 to 4 measured students' level of depression. According to results, the students reported that, on average, they experience low levels of depression. Descriptive results showed that the majority of students $(90 \%)$ plan to go to college after graduating from high school. For past victimization, on average, only a small proportion of students experienced victimization once or more times. Furthermore, the results of the binary correlation analysis indicated that all independent and control variables are significantly related to truancy except economic deprivation.

\subsection{Ordinal Logistic Regression Results}

Table 3 presents results of the ordinal logistic regression analysis, reporting the likelihood of unexcused school absenteeism by regressing it on strain variables and control variables. As mentioned earlier, we established six different models. The first two models were conducted using the total sample, whereas the rest of the models were conducted with gender subsamples. While the first, third and fifth models included only independent variables as main predictors of students' unexcused school absenteeism, control variables were introduced in other models to increase the explanatory power of the analyses.

For the total sample, the second model is the best fit given its higher chi square value $(X 2=213.31$, $\mathrm{p}<.001)$, lower $-2 \log$ likelihood values $(-2290)$ and higher Pseudo R2 values $(\mathrm{R} 2=.09)$ than model 1 . The results indicate that as school strain increases, the likelihood of chronic truancy increases holding all other variables constant $(\mathrm{OR}=1.59, \mathrm{p}<.001)$. Similarly, the higher number of negative life events leads to an increase in the likelihood chronic absenteeism, all else equal $(\mathrm{OR}=1.15$, $\mathrm{p}<.001)$. While depression has no significant effect on the dependent variable, anger is positively related to the likelihood of school truancy $(\mathrm{OR}=1.63, \mathrm{p}<.001)$. In addition, it appears that students who have a college goal after graduation are less likely to engage in chronic truancy than those who have no college goal, controlling all other variables $(\mathrm{OR}=.67, \mathrm{p}<.05)$. On the other hand, as seen on table 4, economic deprivation and victimization have no significant effect on school truancy. For control variables, male students are more likely to be involved in chronic school truancy than female students $(\mathrm{OR}=1.83, \mathrm{p}<.001)$. In addition, age has a negative relationship with likelihood of 
Solakoglu O.,\& Orak, U. (2016). School truancy among Turkish high school students: A test of General Strain Theory. International Journal of Human Sciences, 13(1), 1460-1472. doi:10.14687/ijhs.v13i1.3670

Table 3: Ordinal Logistic Regression Predicting School Truancy among Turkish Adolescents

\begin{tabular}{|c|c|c|c|c|c|c|c|c|c|c|c|c|}
\hline & \multicolumn{4}{|c|}{ Total Sample (N=1906) } & \multicolumn{4}{|c|}{ Male $(\mathrm{N}=966)$} & \multicolumn{4}{|c|}{ Female $(\mathrm{N}=940)$} \\
\hline & \multicolumn{2}{|c|}{$\underline{\text { Model } 1}$} & \multicolumn{2}{|c|}{ Model 2} & \multicolumn{2}{|c|}{$\underline{\text { Model } 3}$} & \multicolumn{2}{|c|}{$\underline{\text { Model } 4}$} & \multicolumn{2}{|c|}{$\underline{\text { Model } 5}$} & \multicolumn{2}{|c|}{$\underline{\text { Model } 6}$} \\
\hline & $\underline{\mathrm{OR}}$ & $\underline{\mathrm{SE}}$ & $\underline{\mathrm{OR}}$ & $\underline{\mathrm{SE}}$ & $\underline{\mathrm{OR}}$ & $\underline{\mathrm{SE}}$ & $\underline{\text { OR }}$ & $\underline{\mathrm{SE}}$ & $\underline{\mathrm{OR}}$ & $\underline{\mathrm{SE}}$ & $\underline{\mathbf{O R}}$ & $\underline{\mathrm{SE}}$ \\
\hline $\begin{array}{l}\text { School } \\
\text { Strain }\end{array}$ & $1.80 * * *$ & 0.14 & $1.59 * * *$ & 0.12 & $1.53 * * *$ & 0.14 & $1.46 * * *$ & 0.14 & $1.97 * * *$ & 0.27 & $1.92 * * *$ & 0.26 \\
\hline $\begin{array}{l}\text { Negative } \\
\text { Life Events }\end{array}$ & $1.16 * * *$ & 0.05 & $1.15^{* * *}$ & 0.05 & $1.12 *$ & 0.06 & $1.12 *$ & 0.06 & $1.27 * *$ & 0.10 & $1.25 * *$ & 0.10 \\
\hline $\begin{array}{l}\text { Economic } \\
\text { Strain }\end{array}$ & 0.97 & 0.06 & 0.92 & 0.06 & 0.98 & 0.07 & 0.97 & 0.07 & 0.85 & 0.09 & 0.83 & 0.09 \\
\hline Anger & $1.67 * * *$ & 0.14 & $1.63 * * *$ & 0.13 & $1.69 * * *$ & 0.18 & $1.65 * * *$ & 0.17 & $1.52 * *$ & 0.21 & $1.52 * *$ & 0.21 \\
\hline Depression & $0.79 * *$ & 0.07 & 0.89 & 0.08 & 0.85 & 0.09 & 0.84 & 0.09 & 0.97 & 0.14 & 0.96 & 0.14 \\
\hline $\begin{array}{l}\text { College } \\
\text { Plans }\end{array}$ & $0.60 * *$ & 0.10 & $.67 *$ & 0.11 & $0.62 *$ & 0.12 & $0.61 *$ & 0.12 & 0.85 & 0.30 & 0.88 & 0.32 \\
\hline $\begin{array}{l}\text { Victimizatio } \\
\mathrm{n}\end{array}$ & 1.08 & 0.07 & 1.05 & 0.07 & 0.98 & 0.09 & 0.96 & 0.08 & 1.23 & 0.14 & 1.23 & 0.14 \\
\hline $\begin{array}{l}\text { Gender } \\
(1=\text { Male })\end{array}$ & & & $1.83 * * *$ & 0.24 & & & & & & & & \\
\hline Age & & & $.70 * * *$ & 0.06 & & & $0.66 * * *$ & 0.06 & & & 0.79 & 0.12 \\
\hline $\begin{array}{l}\text { Both } \\
\text { Parents } \\
\end{array}$ & & & $.65 *$ & 0.13 & & & 0.74 & 0.18 & & & 0.56 & 0.19 \\
\hline Pseudo $\mathrm{R}^{2}$ & 0.06 & & 0.09 & & 0.05 & & 0.06 & & 0.08 & & 0.08 & \\
\hline Model X $\mathrm{X}^{2 * *}$ & 158.81 & & 213.31 & & 70.29 & & 89.71 & & 72.56 & & 77.48 & \\
\hline $\begin{array}{l}-2 \log \\
\text { likelihood }\end{array}$ & -2345 & & -2290 & & -1438 & & -1419 & & -864 & & -859 & \\
\hline
\end{tabular}

school truancy $(\mathrm{OR}=.70, \mathrm{p}<.001)$ Moreover, students who live with their both parents are less likely to engage in chronic truancy than those who live in different arrangements $(\mathrm{OR}=.65, \mathrm{p}<.05)$.

Focusing on results from the male subsample, it appears that model 4 has more explanatory power than model 3 given its higher values of Pseudo R2 (.06) and X2 (89.71, p<.001) and lower values of -2 likelihood (-1481) in comparison to model 3. Similar to the total sample, school strain $(\mathrm{OR}=.1 .53, \mathrm{p}<.05)$, number of negative life events $(\mathrm{OR}=1.12, \mathrm{p}<.05)$, and level of anger $(\mathrm{OR}=1.65, \mathrm{p}<.001)$ increases the likelihood of school truancy, all else equal. On the other hand, having college plans $(\mathrm{OR}=.61, \mathrm{p}<.05)$ and age $(\mathrm{OR}=.68, \mathrm{p}<.001)$ has a negative relationship with likelihood of school truancy. Parallel with model 3, depression, economic deprivation and victimization have no significant effect on likelihood of school truancy. Moreover, family structure has no significant effect on the dependent variable despite its significant relationship in the total sample.

For the female subsample, model 6 , which has both independent variables and control variables, is a better fitting model than model 5 (Pseudo R2 =09; X2 77.48, $\mathrm{p}<.001 ;-2$ likelihood $=-858.86$ ). Similar to model 2 and model 4, school strain, number of negative life events, and anger are significantly and positively related to likelihood of chronic truancy. However, the significance of having college plans disappears in the female subsample. In addition, none of the control variables were significant predictors in model 6 . 


\section{DISCUSSION}

Findings revealed that certain kinds of strain could trigger the unexcused school absenteeism among Turkish adolescents. According to results of ordered logistic regression analysis, among strain variables, school strain, negative life events, anger, and college plans were significantly associated with unexcused school absenteeism for the total sample. The relationships were positive for all variables except college plans. Contrary to our expectations, however, economic deprivation, depression, and past victimization had no effect on students' unexcused school absenteeism. We found that age and gender were also significantly associated with the dependent variable, while family structure had no effect. Taking gender subsamples into account, school strain, negative life events and anger had a significant effect on unexcused absenteeism for both males and females, whereas college plans had an effect for males but not females. These findings highlighted the importance of having future goals to reduce delinquency for males. Findings were also compatible with the study of Altnkurt (2008) highlighting the roles of school strain, negative life events from family, psychological disorders in understanding truancy. In addition, results supported the study of Pehlivan (2013) discussing that problems stemming from school environment cause truancy. The current study provided evidences for the literature of General Strain Theory founded by Agnew (2002) as well.

These findings may have important implications for policy makers and researchers. First, according to the descriptive statistics results, a considerable amount of students reported that they have been absent from classes without any reason for at least one whole day. This is an important implication in terms of exploring the magnitude of the problem in Turkey. Considering the destructive consequences of school absenteeism, which vary from school drop-outs to lower opportunities in job market, results of this study can be crucial for policy makers in order to understand causes of this issue and find solutions. Secondly, we demonstrated that causes of risk behaviors in an educational context can be understood using Agnew's General Strain Theory, which suggests significant relationships between school absenteeism and certain kinds of strain. Finally, we tested and showed evidence for generalizability of the theory in countries with different economic conditions, social structures, and cultural values from the United States.

It is important to note some limitations of the present study. The first concerns the generalizability of our results. Since this study was limited to the context of Turkey, a caution is advised in generalizing the results to other countries. In addition, this study lacks certain demographic variables when compared to similar studies conducted in other countries. Race and ethnicity, for instance, was not included in the analysis. Since there are very few different racial minorities, race is not regarded as an issue and not studied by researchers in Turkey. Since race was not included as a variable in the dataset, we could not operationalize this variable for our study. Another variable not included in the analysis was social class. Since class boundaries are not as strong in Turkey as in the United States, similar to race, social class was not regarded as an issue and not included in the survey. For this reason, we could not use social class as a variable in our study. All independent variables and explanatory variables, however, were operationalized appropriately.

Secondly, since the Youth in Europe Survey is a self-reported dataset, this study may have all the limitations that can occur with self-reported data. Self-reported data may contain several potential sources of biases. For example, adolescents may tend to respond to questions in a manner that will be viewed favorably by others, a validity problem known as social desirability. This bias may interfere with the interpretation of average tendencies as well as individual differences. Respondents, may also have a selective memory, meaning they might not remember their past experiences or remember them incorrectly. They might also try to portray events they witnessed as more significant than those in reality. Despite these limitations noted above, this study can be very valuable for both policy makers and researchers who are interested in education and criminology. 
Given the results of this study, further research is needed to develop our findings. First, our findings on the potential variation in unexcused school absenteeism were deduced from an examination of high school students in Istanbul city. Conducting studies in larger and more diverse populations would provide an opportunity to show the influence of certain kinds of strain on students' unexcused school absenteeism. Secondly, since geographical positions of different cities may lead students to school absenteeism for several reasons, the study should be replicated in other geographical areas of Turkey in order to observe the neighborhood effects. Since some cultural values dictate that schooling is unnecessary for girls in Turkey, examining the issue in other cities, especially in eastern cities of the country, might also be beneficial to determine the effects of strain stemming from cultural beliefs on school absenteeism. In addition, future studies should assess peer dynamics as part of the absenteeism problem given that following their peers may lead students to be absent without a qualified excuse. Future studies should also examine teachers' and parents' perceptions of school attendance in order to triangulate them with findings of this study. Finally, although we found significant associations between unexcused school absenteeism and school strain, negative life events, anger, and college plans, we did not find any effect for economic deprivation, depression, and past victimization, contrary to the literature. Further studies should also examine the effect of these variables on unexcused school absenteeism more deeply.

\section{CONCLUSION}

This study examined unexcused school absenteeism among Turkish high school students. Recently, as in the U.S., school absenteeism has been a growing concern in developing countries. However, most of studies related to school absenteeism have been conducted in an American context. For this reason, the current study examined the issue in the Turkish context. Although there are many studies indicating the various causes for unexcused school absenteeism, our study employed a unique approach by examining the issue from a criminological perspective and through the lens of Agnew's General Strain Theory. Using this strategy, we showed the applicability of General Strain Theory to educational issues and also tested the generalizability of the theory to countries with different economic, social, and cultural structures.

\section{REFERENCES}

Adıgüzel, A. (2013). Kız çocuklarının okullulaşma engelleri ve çözüm önerileri (Şanlıurfa Örneği). Ekeve Akademisi Dergisi, 17 (56), 325-344.

Agnew, R. (1992). Foundation for a general strain theory of crime and delinquency. Criminology, 30 (1), 47-88.

Agnew, R. (2006). Pressured into crime: An overview of general strain theory. Oxford University Press, USA.

Altınkurt, Y. (2008). Öğrenci devamsızlıklarının nedenleri ve devamsızlığın akademik başarıya olan etkisi. Sosyal Bilimler Dergisi, 20, 129-142.

Aseltine Jr, R. H., Gore, S., \& Gordon, J. (2000). Life stress, anger and anxiety, and delinquency: An empirical test of general strain theory. Journal of Health and Social Behavior, 256-275.

Baker, M. L., Sigmon, J. N., \& Nugent, M. E. (2001). Truancy Reduction: Keeping Students in School. Juvenile Justice Bulletin. Retrieved December 20, 2014, from http://eric.ed.gov/?id=ED468296

Beyth-Marom, R., Austin, L., Fischhoff, B., Palmgren, C., \& Jacobs-Quadrel, M. (1993). Perceived consequences of risky behaviors: adults and adolescents. Developmental Psychology, 29(3), 549_ 563.

Braithwaite, J. (1981). The myth of social class and criminality reconsidered. American Sociological Review, 46(1), 36.

Broidy, L. M. (2001). A test of general strain theory. Criminology, 39(1), 9-36. 
Solakoglu O.,\& Orak, U. (2016). School truancy among Turkish high school students: A test of General Strain Theory. International Journal of Human Sciences, 13(1), 1460-1472. doi:10.14687/ijhs.v13i1.3670

Cloward, R. A., \& Ohlin, L. E. (1959). New Perspectives on Juvenile Delinquency.

Cohen, A. K. (1955). Delinquent boys; the culture of the gang. New York, NY, US: Free Press.

DeKalb, J. (1999). Student Truancy. ERIC Digest, Number 125. Retrieved December 20, 2014, from http://eric.ed.gov/?id=ED429334

Eaton, D. K., Brener, N., \& Kann, L. K. (2008). Associations of health risk behaviors with school absenteeism. Does having permission for the absence make a difference? Journal of School Health, 78 (4), 223-229.

Egger, H. L., Costello, J. E., \& Angold, A. (2003). School refusal and psychiatric disorders: a community study. Journal of the American Academy of Child \& Adolescent Psychiatry, 42(7), 797807.

Fantuzzo, J., Grim, S., \& Hazan, H. (2005). Project start: An evaluation of a community-wide school-based intervention to reduce truancy. Psychology in the Schools, 42(6), 657-667.

Gage, N. A., Sugai, G., Lunde, K., \& DeLoreto, L. (2013). Truancy and zero tolerance in high school: does policy align with practice? Education and Treatment of Children, 36(2), 117-138.

Ingul, J. M., Klöckner, C. A., Silverman, W. K., \& Nordahl, H. M. (2012). Adolescent school absenteeism: modelling social and individual risk factors. Child and Adolescent Mental Health, 17(2), 93-100.

Ingul, J. M., \& Nordahl, H. M. (2013). Anxiety as a risk factor for school absenteeism: what differentiates anxious school attenders from non-attenders? Annals of General Psychiatry, 12(1), 25.

Kearney, C. (2008). School absenteeism and school refusal behavior in youth: A contemporary review. Clinical Psychology Review, 28(3), 451-471.

Kiran, H. (2000). Sekiz yıllık zorunlu eğitim uygulamasında karşılaşılan sorunlar. Pamukkkale University Department of Education Journal, 7(14), 80-83.

Kleck, G. (1982). On the use of self-report data to determine the class distribution of criminal and delinquent behavior. American Sociological Review, 47(3), 427.

Kubrin, C. E., Stucky, T. D., \& Krohn, M. D. (2008). Researching theories of crime and deviance (1st edition.). New York, NY: Oxford University Press.

Merton, R. K. (1938). Social structure and anomie. American Sociological Review, 3(5), 672.

Patchin, J. W., \& Hinduja, S. (2010). Traditional and nontraditional bullying among youth: A test of general strain theory. Youth \& Society.

Pehlivan, Z. (2006). Resmi genel liselerde öğrenci devamsızlı̆̆ ve buna dönük okul yönetimi politikaları (Ankara ili örneği). Yayımlanmamış doktora tezi, Ankara Üniversitesi Eğitim Bilimleri Enstitüsü, Ankara.

Piquero, N. L., \& Sealock, M. D. (2004). Gender and general strain theory: A preliminary test of Broidy and Agnew's gender/GST hypotheses. Justice Quarterly, 21(1), 125-158.

Polat, Serdar. (2013). Ortaögretim izleme ve degerlendirme raporu (Secondary School Tracking and Evaluation Report) (No.2014_02).Turkish Ministry of National Education. Retrieved from http://ogm.meb.gov.tr/meb iys dosyalar/2014 02/14013735 ortaretimrapor2013.pdf

Reid, J. A., \& Piquero, A. R. (2013). Applying general strain theory to youth commercial sexual exploitation. Crime \& Delinquency, 0011128713498213.

Sigfusdottir, I. D., Kristjansson, A. L., \& Agnew, R. (2012). A comparative analysis of general strain theory. Journal of Criminal Justice, 40(2), 117-127.

Smith, D. A. (1979). Sex and deviance: an assessment of major sociological variables. Sociological Quarterly, 20(2), 183-195.

Steinhart, D. J. (1996). Status offenses. The Future of Children, 6(3), 86-99.

Tittle, C. R., \& Meier, R. F. (1990). Specifying the SES/delinquency relationship. Criminology, 28(2), 271-300.

Yilmaz, M., Lo, C. C., \& Solakoğlu, Ö. (2015). Cigarette Use by Turkish Adolescents and Its Links to Strain, Depression, and Anger. Journal of Drug Issues, 45(4), 396-408. 